\title{
Notas sobre o tipo de Trigona limao Smith (Hymenoptera, Apidae, Lestrimelitta) ${ }^{1}$
}

\author{
Paola Marchi ${ }^{2,3}$ \& Gabriel A. R. Melo ${ }^{2,4}$
}

\begin{abstract}
${ }^{1}$ Contribuição $n^{\circ} 1468$ do Departamento de Zoologia, Universidade Federal do Paraná.
${ }^{2}$ Departamento de Zoologia, Universidade Federal do Paraná. Caixa Postal 19020, 81531-980 Curitiba-PR, Brasil.

${ }^{3}$ Programa de Pós-Graduação em Entomologia. Bolsista do CNPq.

${ }^{4}$ Pesquisador do CNPq.
\end{abstract}

\begin{abstract}
Notes on the type specimen of Trigona limao Smith (Hymenoptera, Apidae, Lestrimelitta). The name limao has been loosely associated with a variety of forms within the bee genus Lestrimelitta. The identity of the type species was checked through comparisons of Smith's type material with the morphospecies recognized in an ongoing revision of the Brazilian species. Lestrimelitta limao is a species restricted to the cerrados of central Brazil, distributed from São Paulo to Maranhão. It can be distinguished from other species by the following features: vertex almost lacking erect setae; erect setae on anterior margin of mesoscutum restricted to its lateral portions and almost lacking from the middle; lateral portion of mesepisternum with only short, decumbent microsetae; opening of propodeal spiracle with an oval contour, about $2.5 \mathrm{x}$ longer than wide; lateral portion of propodeum covered by dense whitish decumbent pubescence, setae short and mostly plumose; midtibial spur vestigial; metasomal tergum 1 with erect setae on its lateral portions. A lectotype is designated for Trigona limao Smith, 1863.
\end{abstract}

KEYwords. Brazil; Meliponina; Neotropical; stingless bee; taxonomy.

Resumo. O nome limao tem sido usado para espécies distintas do gênero Lestrimelitta. O material-tipo de Smith depositado no The Natural History Museum (Londres) foi examinado. A operária de L. limao é descrita e o lectótipo para Trigona limao Smith, 1863 é designado. Esta espécie encontra-se restrita aos cerrados da porção central do Brasil, de São Paulo ao Maranhão. Distingue-se de outras espécies pelos seguintes caracteres diagnósticos: vértice com pouquíssimas cerdas eretas, muito finas e curtas, restritas à região interocelar; bordo anterior do mesoscuto com cerdas eretas castanhas nas laterais; laterais do mesepisterno com cerdas eretas esparsas e restritas à porção ventral e curvatura entre porções lateral e ventral, tornando-se mais longas próximo à base da coxa média; contorno da abertura do espiráculo propodeal, aproximadamente 2,5 x mais longo do que largo; flancos do propódeo coberto por pilosidade decumbente esbranquiçada, fina e ramificada; esporão mesotibial muito reduzido; tergo metassomal 1 com cerdas enegrecidas nas porções laterais.

Palavras-Chave. Abelhas sem ferrão; Brasil; Meliponina; Neotropical; taxonomia.

O gênero Lestrimelitta (Friese, 1903) foi revisto pela última vez por SchWARZ (1948), que considerou como válidas apenas duas espécies, L. ehrhardti Friese, 1931 e L. limao (Smith, 1863), esta última com ampla distribuição, do México ao sul do Brasil, Paraguai e norte da Argentina. Posteriormente CAmArgo \& Moure (1989), ao descreverem duas novas espécies da região amazônica, comentaram que L. limao sensu Schwarz (1948) apresenta uma grande variação de formas e combinações de caracteres que parecem indicar que se trata de um repositório de espécies distintas. Dentre os autores mais recentes, Ayala (1999) foi o único a contribuir para o esclarecimento da identidade de L. limao. Ao examinar o material-tipo, esse autor observou que $L$. limao foi incorretamente citada para o México e que a verdadeira $L$. limao teria distribuição restrita à América do Sul, pois apresenta, entre outros caracteres, o espiráculo do propódeo muito largo e aberto, enquanto nas espécies do México e América Central, é longo e estreito.

É interessante chamar atenção para algumas informações de cunho histórico. Em um esforço do Imperador D. Pedro II, de tornar o país conhecido e com uma imagem mais civilizada, o Brasil participou, pela primeira vez, da $3^{\text {a }}$ edição das 'Exposições Universais', em Londres, 1862, onde foram selecionadas amostras de café, mate, borracha, pedras preciosas, madeiras, máquinas, abelhas, entre outras, selecionadas das várias províncias para uma mostra nacional (Almeida 2000). A partir do material exposto em Londres, Frederick Smith descreveu espécies do gênero Melipona Illiger, 1806 e Trigona Jurine, 1807, entre elas Trigona limâo [sic], usando seu nome vernacular "limão" (Sмітн 1863).

Sмiтн (1863) descreveu T. limao com base em exemplares que julgava serem machos porém, de acordo com SCHWARZ (1948: 90), o espécime marcado como 'tipo', depositado no The Natural History Museum (Londres), é uma operária. É compreensível a confusão feita por Smith, pois as operárias deste gênero se parecem com machos em vários aspectos, como a ausência da corbícula e a fronte convexa.

$\mathrm{Na}$ descrição original, os dados de procedência indicam apenas 'Brazil', não sendo possível sua localização geográfica precisa. Como Sмiтн (1863) utilizou os nomes vernaculares para denominar as espécies, pela etimologia, possivelmente o material seja proveniente do sudeste (CAMARGO \& MOURE 1996: 110).

O objetivo deste trabalho é esclarecer as dúvidas relacionadas à identidade de L. limao, a partir do estudo de material-tipo, com a descrição da operária. Como na descrição original, Smith não indicou quantos exemplares foram 
examinados, é pertinente designar o exemplar marcado como "type" no The Natural History Museum (Londres) como lectótipo de Trigona limao, de modo a estabilizar a nomenclatura do grupo.

$\mathrm{Na}$ descrição, dp significa diâmetro do ponto e $\mathrm{T}$, tergo metassomal.

Os acrônimos das instituições depositárias e respectivos pesquisadores responsáveis são: (BMNH) The Natural History Museum, Department of Entomology (British Museum, Londres, UK), Mr. George Else; (DZUP) Coleção de Entomologia Pe. J. S. Moure, Departamento de Zoologia, Universidade Federal do Paraná (Curitiba, Paraná, Brasil), Dr. Gabriel A. R. de Melo; (LEA) Laboratório de Estudos Sobre Abelhas, Departamento de Biologia, Universidade Federal do Maranhão (São Luís, Maranhão, Brasil), Dr ${ }^{\mathrm{a}}$ Lenira Lacerda; (RPSP) Coleção Camargo, Departamento de Biologia, Faculdade de Filosofia, Ciências e Letras de Ribeirão Preto, Universidade de São Paulo (Ribeirão Preto, São Paulo, Brasil), Dr. João M. F. de Camargo; (RAW) Coleção particular do Dr. Anthony Raw, atualmente na Universidade Estadual de Santa Cruz (Ilhéus, Bahia, Brasil).

\section{Lestrimelitta limao (Smith, 1863)}

(Figs. 1-3)

Trigona limâo [sic] F. Smith, 1863: 504, 506.

Trigona limao; Ihering, 1902: 384, 386 (partim).

Trigona (Lestrimelitta) limao; Friese, 1903: 361; Marianno, 1911: 139, 140; Schwarz, 1938: 451 (partim).

Lestrimelitta limao; Schwarz, 1948: 182-191 (partim); Lucas de Oliveira, 1964: 39; 1968: 2; Roubik, 1980: 264 (partim); Almeida \& Laroca, 1982: 41 (partim); Camargo \& Moure, 1989: 195, 196, 198, 202204, 207, 208 (partim); Michener, 1990: 117, 118; 2000: 787 (partim); Ayala, 1999: 1, 29, 32; Oliveira, 2002: 197 (partim); Silveira et al., 2002: 88; Costa et al., 2003: 75, 77-80

Diagnose. Vértice com pouquíssimas cerdas eretas, muito finas e curtas, restritas à região interocelar; lobos pronotais e bordo anterior das tégulas com cerdas eretas longas $(0,1-0,13$ $\mathrm{mm}$ ); bordo anterior do mesoscuto com cerdas eretas castanhas nas laterais $(0,20 \mathrm{~mm})$ e pouquíssimas cerdas muito curtas e finas na porção medial; laterais do mesepisterno apenas com microcerdas semi-decumbentes $(0,02 \mathrm{~mm})$, cerdas eretas esparsas e restritas à porção ventral e curvatura entre porções lateral e ventral $(0,05 \mathrm{~mm})$, tornando-se mais longas $(0,12-0,14$ $\mathrm{mm}$ ) próximo à base da coxa média; contorno da abertura do espiráculo propodeal, em vista látero-posterior, ovalado (Fig. 3 ), aproximadamente 2,5 x mais longo do que largo; flancos do propódeo coberto por pilosidade decumbente esbranquiçada, fina e ramificada; esporão mesotibial vestigial, porém visível e enegrecido; metassoma com cerdas enegrecidas nas laterais de todos os tergos, as mais longas de $\mathrm{T} 1 \mathrm{com}$ cerca de $0,10 \mathrm{~mm}$, e tornando-se gradativamente mais longas nos demais.

Descrição da operária (baseada em espécime de Betim, Minas Gerais).

Dimensões. Comprimento total aproximado, 5,9 mm; comprimento da asa anterior, a partir do esclerito costal, 4,1 $\mathrm{mm}$; largura máxima da cabeça, $2,1 \mathrm{~mm}$.

Cor do integumento. Predominantemente castanhoenegrecido; face ventral dos escapos e flagelos castanhos; mandíbulas castanho-avermelhadas, enegrecidas no bordo anterior; coxas, trocanteres, base dos fêmures, extremidade distal dos fêmures anteriores, tarsos, terço inferior das tíbias posteriores, área basal do propódeo e os quatro primeiros esternos abdominais castanhos; metade basal de T1 e porções laterais de T1 e T2 castanhas; membrana alar levemente tingida de castanho, pterostigma e veias alares castanhos.

Pilosidade. Microcerdas na face tão curtas como o diâmetro dos pontos, um pouco mais longas $(0,02 \mathrm{~mm})$ e decumbentes nas genas; vértice com pouquíssimas cerdas eretas, muito finas e curtas (no máximo $0,05 \mathrm{~mm}$ ), restritas à região interocelar; cerdas esparsas muito curtas, em torno de $0,03 \mathrm{~mm}$, ao longo do rebordo preoccipital; algumas cerdas eretas, finas e amareladas de $0,05 \mathrm{~mm}$ no ápice dos escapos. Lobos pronotais com algumas cerdas eretas enegrecidas, com cerca de $0,13 \mathrm{~mm}$; no bordo inferior, no limite com o mesepisterno, pilosidade plumosa amarelada curta. Cerdas eretas castanhas no bordo anterior das tégulas com cerca de $0,1 \mathrm{~mm}$. Bordo anterior do mesoscuto com cerdas eretas castanhas de $0,20 \mathrm{~mm}$ nas laterais e pouquíssimas cerdas muito curtas e finas na porção medial; no disco, apenas microcerdas semi-decumbentes, com cerca de $0,02 \mathrm{~mm}$; nos bordos laterais, cerdas eretas e curtas, as anteriores com aproximadamente $0,06 \mathrm{~mm}$ e as posteriores, próximo às axilas, um pouco mais longas $(0,12-0,14 \mathrm{~mm})$. Escutelo com cerdas eretas muito curtas e esparsas no disco; no bordo posterior, uniformemente castanhas e com até $0,17 \mathrm{~mm}$. Laterais do mesepisterno apenas com microcerdas semi-decumbentes, com cerca de $0,02 \mathrm{~mm}$; porção acima do sulco mesepisternal parcialmente glabra; cerdas eretas esparsas, restritas à porção ventral e curvatura entre porções lateral e ventral do mesepisterno, com cerca de $0,05 \mathrm{~mm}$, tornando-se mais longas $(0,12-0,14 \mathrm{~mm})$ próximo à base da coxa média. Nos $2 / 3$ superiores do metepisterno decumbente e esbranquiçada, predominantemente ramificada; na porção inferior, simples e curta; as duas porções separadas por uma estreita faixa longitudinal glabra, estreitamente interrompida ao longo da sutura pleural por microcerdas simples. Nos flancos do propódeo, pilosidade decumbente como na porção superior do metepisterno, mais ramificada junto ao espiráculo propodeal; com poucas cerdas eretas nas porções inferior e posterior. Tíbias médias com pilosidade decumbente fina, mais longa que nas tíbias anteriores; com algumas cerdas eretas muito curtas $(0,05$ $\mathrm{mm}$ ) na face externa; nos bordos anterior e posterior, cerdas eretas uniformemente castanhas e mais longas, principalmente no ápice. Fêmures posteriores com cerdas eretas, de 0,1 a 0,14 $\mathrm{mm}$ de comprimento, uniformemente distribuídas por toda a face externa. Cerdas do bordo posterior das tíbias posteriores castanho-amareladas, as mais longas com $0,20 \mathrm{~mm}$, algumas com uma ou duas ramificações curtas na parte mediana da cerda; no bordo anterior, cerdas um pouco mais curtas. Metassoma com cerdas enegrecidas nas laterais de todos os tergos, as mais longas do $\mathrm{T} 1 \mathrm{com}$ cerca de $0,10 \mathrm{~mm}$, e tornando-se gradativamente mais longas nos demais. Bordo posterior de 

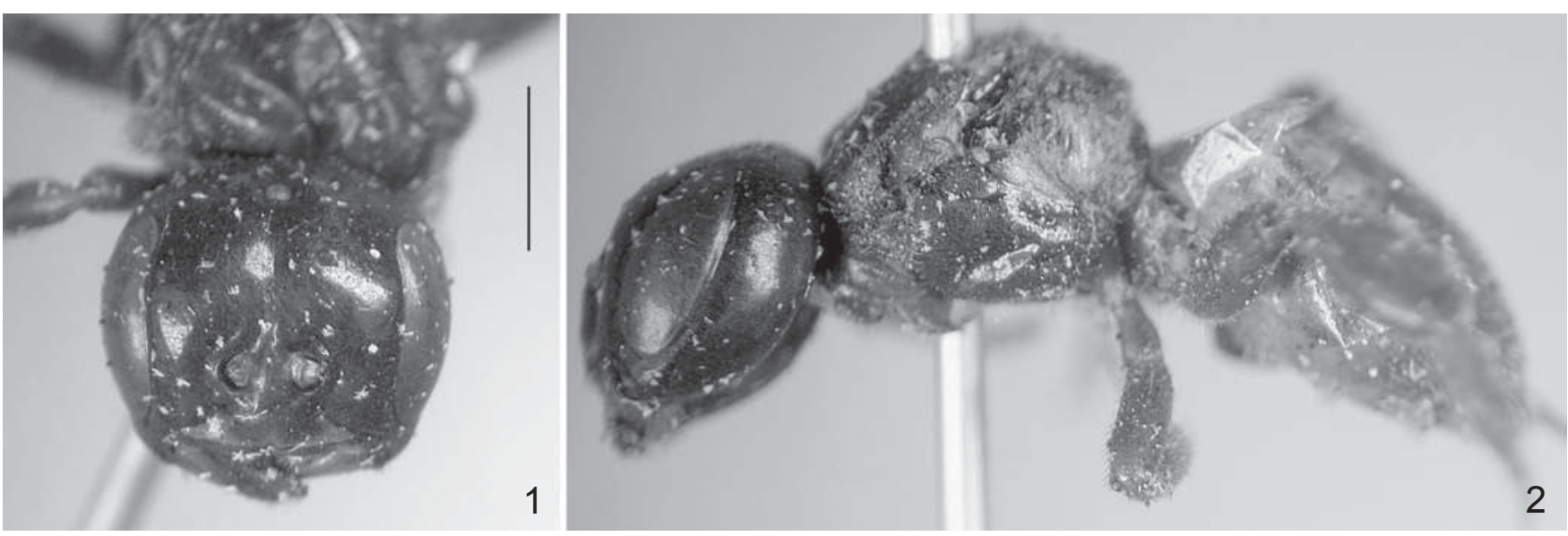

Figs. 1-2. Lectótipo de Trigona limao Smith, 1863. 1, vista frontal; 2, vista lateral. Escala=1 mm.

T1 glabro; de T2, com pouquíssimas cerdas muito curtas, esparsas lateralmente e ausentes na porção medial; nos demais tergos, cerdas gradativamente mais longas e mais densas; T6 uniformemente cerdoso, cerdas castanho-escuras, algumas delas com um ou dois ramos subapicais, as mais longas com cerca de $0,22 \mathrm{~mm}$.

Pontuação. Muito fina e pouco conspícua na cabeça; extremamente esparsa na regiões paroculares inferior e média; mais densa na porção superior da fronte e vértice, pontos menores separados por $2 \mathrm{a} 4 \mathrm{dp}$, pontos maiores por 0,04 a 0,1 $\mathrm{mm}$; no clípeo, 3 a $5 \mathrm{dp}$; na gena, pontos separados por menos de uma vez o comprimento das microcerdas. Mais esparsa no mesepisterno, pontos separados por uma a duas vezes o comprimento das microcerdas.

Medidas e proporções (em mm). Cabeça mais larga do que longa e mais larga que o tórax $(2,10: 1,66: 1,71)$; órbitas internas levemente divergentes inferiormente $(1,39: 1,42)$; olhos mais longos que sua largura máxima $(1,25: 0,60)$; largura dos olhos em vista lateral menor que a largura máxima das genas $(0,41: 0,60)$; clípeo aproximadamente 3 vezes mais largo que longo $(1,37: 0,38) ; 1^{\circ}$ flagelômero quase 2 vezes mais longo que o $2^{\circ}$ $(0,14: 0,08)$, um pouco maior na largura $(0,17: 0,15)$; distância interalveolar (distância mínima) igual ao diâmetro do alvéolo $(0,19: 0,19)$; distância entre os ocelos laterais aproximadamente 2 vezes o diâmetro do ocelo médio $(0,37: 0,15)$; área malar (distância mínima) pouco menor que o diâmetro do escapo $(0,12: 0,13)$; escutelo mais largo (distância do bordo anterior) que longo $(0,62: 0,49)$; basitarsos médios 5 vezes mais longos que sua largura máxima $(0,75: 0,15)$; tíbias posteriores aproximadamente 3 vezes mais longas que sua largura máxima $(1,42: 0,50)$; basitarsos posteriores aproximadamente 3 vezes mais longos que sua largura máxima $(0,79: 0,31)$ e 2 vezes mais largos que os médios $(0,31: 0,13)$; contorno da abertura do espiráculo propodeal, em vista látero-posterior, ovalado, aproximadamente $2,5 \mathrm{x}$ mais longo do que largo $(0,19: 0,07)$; esporão mesotibial vestigial (com aproximadamente $0,05 \mathrm{~mm}$ ), porém visível e enegrecido.
Material-tipo examinado. BRASIL: 1 operária (BMNH), aqui designada como lectótipo, com as seguintes etiquetas 'Type' (etiqueta circular impressa), 'B. M. TYPE HYM. 14 B. 1072', 'Trigona Limao. Sm' (etiqueta azul manuscrita), 'Smith coll. pres. by Mrs. Farren White. 99-303.' A seguinte etiqueta foi adicionada: 'Lectotype, Trigona limao Smith, 1863, des. Marchi \& Melo, 2004'.

Comentários. O lectótipo está muito sujo e danificado, a porção central do mesoscuto e o primeiro tergo estão amassados; faltam as antenas, todas as asas e as pernas anteriores e médias do lado direito (Figs. 1, 2). Contudo, o reconhecimento da espécie é inequívoco, permitindo associar com segurança os espécimes listados abaixo com o nome limao. Os caracteres apresentados na diagnose permitem distingui-la de outras Lestrimelitta.

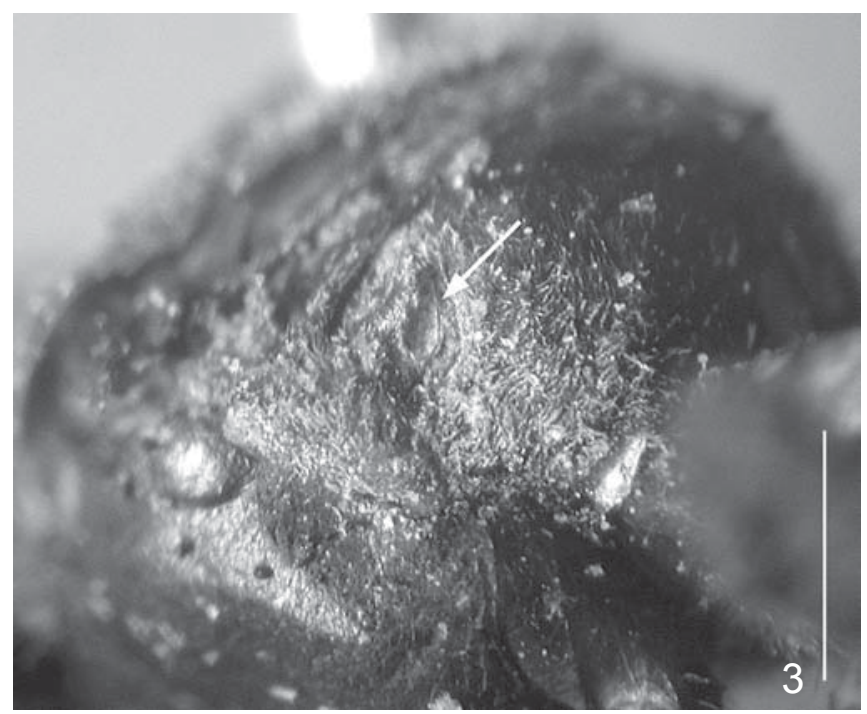

Fig. 3. Espiráculo propodeal, em vista látero-posterior, do lectótipo de Trigona limao. Escala $=0,5 \mathrm{~mm}$. 


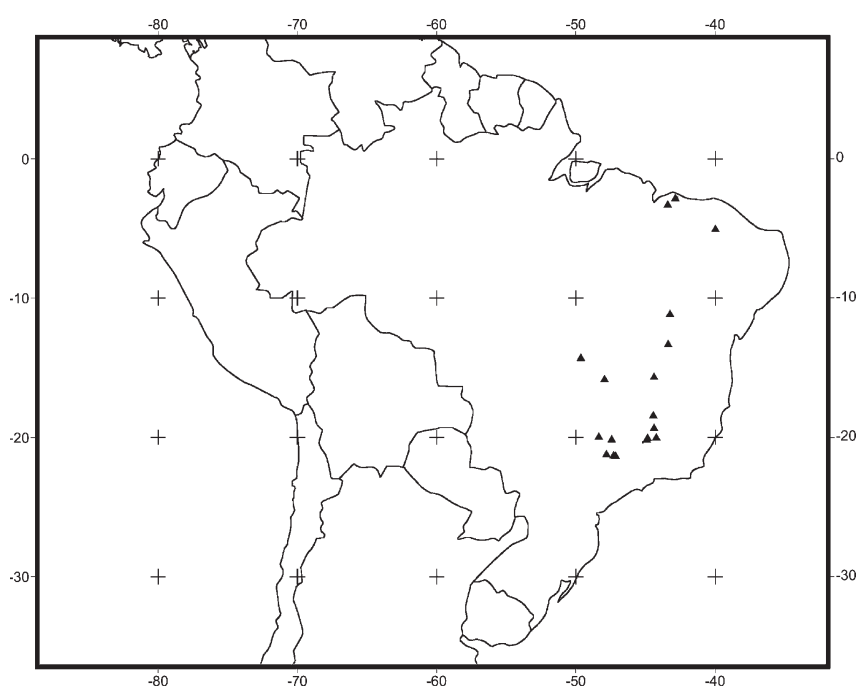

Fig. 4. Distribuição conhecida de Lestrimelitta limao.

Distribuição geográfica. O material disponível indica que esta espécie está restrita aos cerrados da porção central do Brasil (Fig. 4), indo de São Paulo ao Maranhão, incluindo áreas de transição cerrado-caatinga na Bahia.

Material adicional examinado. BRASIL. Maranhão: 2 operárias (DZUP, LEA), 'Br, Ma, Barreirinhas, Tabocas, 20.VII.03, A1-11 N3, Araújo, M. leg'; 1 operária (DZUP), 'Urbano Santos - MA, 27.04.02 BC3, Serra, B. leg'. Ceará: 14 operárias (DZUP), 'Brasil, Ceará, Localidade desconhecida, Prof. Melquiades Pinto Paiva Coll. (Universidade do Ceará, Instituto de Biologia Marinha)'. Bahia: 15 operárias (DZUP), 'B. JESUS DA LAPA, BA, BRASIL, VIII-1961, S. Laroca leg.'; 1 operária e 1 macho, 'Brasil, Bahia, Ibiraba-Barra, 04.ii.2000, Alex Teixeira, Ninho 1 c'. Goiás: 2 operárias (RPSP), 'Campos Verdes, GO, Brasil, 03.VII.1992, S. de Souza, Sete Portas'. Distrito Federal: 6 operárias (DZUP, RAW), 'Brasil, Distrito Federal, Jardim Botânico de Brasília, 3.i.1996, A. Raw'. Minas Gerais: 19 operárias e 10 machos (DZUP), 'Brasil, Minas Gerais, Betim, 20.xii.2001, P. Marchi. ninho'; 4 operárias (DZUP), 'Brasil, Minas Gerais, Corinto, 1-15.xi.1979, C. Elias leg.'; 3 operárias (DZUP),

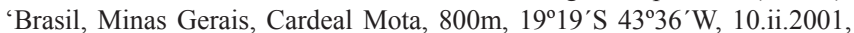
G. A. R. Melo, em ninho'; 1 operária (DZUP), 'S. Gonçalo do Pará - MG, II-1949'; 3 operárias (RPSP), 'P. de M. da Cruz - Mg, 22.vii.1988,

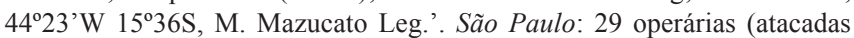
por Tetragonisca angustula) (DZUP), 'Brasil, Ribeirão Preto SP, Campus da USP, 26.ix.2002, Freitas, G. S. col.'; 1 operária (DZUP), 'Brasil, São Paulo, Ribeirão Preto, Campus da USP, 6.XI.1998, Melo'; 1 operária (DZUP), idem, exceto '26.III.1999'; 1 operária (DZUP), idem, exceto '10.ix.2000'; 1 operária (DZUP), 'Brasil, São Paulo, Luís Antonio, Est. Ecol. de Jataí, 16.x.1999, G. A. R. Melo'; 12 operárias (RPSP), 'Faz. Rio Branco, Rifaina - SP, Brasil. 06.X.1990, S. Mateus Leg.'; 2 operárias (RPSP), 'Faz. Sta. Carlota, CAJURU. SP. BRASIL, 22/VIII/1987, S. R. M. Pedro leg'; 2 operárias (RPSP), idem, exceto '23.VII.1987, Camargo, Camargo e Tavares Fo. Leg.'; 5 operárias (RPSP), idem, exceto '20-IV1988, G. C. Venturieri'; 1 operária (RPSP), 'Cássia dos Coqueiros, SP, Brasil, 08/III/1997, Camargo, Pedro leg.' e '970612'.

Agradecimentos. Ao Sr. George Else (BMNH), pelo envio do materialtipo; ao Dr. João M. F. Camargo (USP), pelo empréstimo de material; ao Dr. Anthony Raw (UESC) e Claudivã M. Maia (UFMA) pela doação de espécimes; à Profa. Danúncia Urban (UFPR), pelo incentivo constante e apoio na realização do trabalho; à Elaine Soares (UFPR), pelo auxílio na confecção do mapa.

\section{REFERÊNCIAS}

Almeida, A. O. 2000. Folha de São Paulo. 19 de novembro de 2000 Caderno Mais, p. 25.

Almeida, M. C. \& S. Laroca. 1982. Sobre o macho de Lestrimelitta ehrhardti Friese, espécie cleptobiótica, rara, do Brasil (Apidae, Meliponinae). Dusenia 13(2): 41-45.

Ayala, R. 1999. Revision de las abejas sin aguijon de México (Hymenoptera: Apidae: Meliponini). Folia Entomologica Mexicana 106: $1-123$.

Camargo, J. M. F. \& J. S. Moure. 1989. Duas espécies novas de Lestrimelitta Friese (Meliponinae, Apidae, Hymenoptera) da região amazônica. Boletim do Museu Paraense Emílio Goeldi, Série Zoologia, 5 (2): 195-212.

Camargo, J. M. F. \& J. S. Moure. 1996. Meliponini Neotropicais: O gênero Geotrigona Moure, 1943 (Apinae, Apidae, Hymenoptera), com especial referência à filogenia e biogeografia. Arquivos de Zoologia 33(3): 95-161.

Costa, M. A.; M. A. Del Lama; G. A. R. Melo \& W. S. Sheppard. 2003. Molecular phylogeny of the stingless bees (Apidae, Apinae, Meliponini) inferred from mitochondrial 16rDNA sequences. Apidologie 34: 72-84.

Friese, H. 1903. Neue Meliponiden II. Zeitschrift für Systematische Hymenopterologie und Dipterologie 3: 359-361.

IHERING, H. 1902. As abelhas sociaes do Brasil e suas denominações tupis. Revista do Instituto Histórico e Geográfico de São Paulo 8: 377-388.

Lucas de Oliveira, B. 1964. Descrição das rainhas de Lestrimelitta neotropicais (Hymenoptera-Apoidea). Boletim da Universidade Federal do Paraná, Zoologia, 2(3): 35-49.

LuCAS DE Oliveira, B. 1968. Estádios imaturos de Lestrimelitta neotropicais (Hymenoptera-Apoidea). Boletim da Universidade Federal do Paraná, Zoologia, 3(1):1-12.

Marianno, J. Filho 1911. Ensaio sobre as Meliponidas do Brasil. Rio de Janeiro, Edição do Autor, 140 p.

Michener, C. D. 1990. Classification of the Apidae (Hymenoptera). University of Kansas Science Bulletin 54: 75-164.

Michener, C. D. 2000. The Bees of the World. Baltimore, Johns Hopkins University Press, $913 \mathrm{p}$.

OliveiRA, F. F. 2002. The mesotibial spur in stingless bess: a new character for the systematics of Meliponini (Hymenoptera: Apidae). Journal of the Kansas Entomological Society 75(3): 194-202.

RouBIK, D. W. 1980. New species of Trigona and cleptobiotic Lestrimelitta from French Guiana (Hymenoptera: Apidae). Revista de Biologia Tropical 28(2): 263-269.

Schwarz, H. F. 1938. The stingless bees (Meliponidae) of British Guiana and some related forms. Bulletin of the American Museum of Natural History 74: 437-508.

Schwarz, H. F. 1948. Stingless bees (Meliponidae) of the Western Hemisphere. Bulletin of the American Museum of Natural History 90: 1-546.

Silveira, F. A.; G. A. R. Melo \& E. A. B. Almeida. 2002. Abelhas Brasileiras: Sistemática e Identificação. Belo Horizonte, F. A. Silveira (ed.), $256 \mathrm{p}$.

Sмiтн, F. 1863. Descriptions of Brazilian honey bees belonging of the genera Melipona and Trigona, with samples of their honey and wax, in the Brazilian Court of International Exhibition of 1862. Transactions of the Entomological Society of London 11(1): 497-512.

Recebido em 27.XI.2003; aceito em 15.VI.2004 